\title{
A Preliminary Study on Acoustical Performance of Oil Palm Mesocarp Natural Fiber
}

\section{HANIF Abdul Latif ${ }^{1, a}$, MUSLI Nizam Yahya ${ }^{1, b}$, MOHAMED NAJIB Rafiq ${ }^{1, c}$, MATHAN Sambu ${ }^{1, d}$, MOHD IMRAN Ghazali ${ }^{1, e}$, MOHAMED NASRUL Mohamed Hatta ${ }^{1, f}$}

${ }^{1}$ Advance Dynamic Control Automation Research Group (ADCARe)

Faculty of Mechanical Engineering \& Manufacturing Engineering,

Universiti Tun Hussein Onn Malaysia

ahd130008@siswa.uthm.edu.my, bmusli@uthm.edu.my, ccd100187@siswa.uthm.edu.my, dhd130006@siswa.uthm.edu.my, ${ }^{\text {imran@uthm.edu.my, }{ }^{\mathrm{f}} \mathrm{mnasrul} @ u t h m . e d u . m y . ~}$

Keywords: Sound Absorption, Natural Fiber, Oil Palm Mesocarp, Polyurethane.

\begin{abstract}
As the population increases, the demand of a comfortable environmental such as sound pollution is getting higher. Sound pollutions also have become worsen and creating concerns for many peoples. Due to this problem, synthetic materials as acoustic absorbers still applied as commonly acoustical panels and this material may hazardous to human health and contribute significantly a pollution to the environments. However, researchers have interested in conducting their research on natural fiber to be an alternative sound absorber. This study investigated the potential of oil palm Mesocarp fiber for sound absorbing material. The Mesocarp fibers were mixed with polyurethane (PU) as binder with ratio of 70:30. The thickness was varied in $10 \mathrm{~mm}, 20 \mathrm{~mm}$, $30 \mathrm{~mm}$, and $40 \mathrm{~mm}$. This study also investigated the air gap of $5 \mathrm{~mm}$ and $10 \mathrm{~mm}$ in the sound absorption performance. Impedance Tube Method was used to measure sound absorption coefficient $(\alpha)$. The measurement was done on accordance with ASTM E1050-98, which is the standard test method for impedance and absorption of acoustical materials using a tube. The results showed that the optimum value for Mesocarp fiber is 0.93 . The optimum value obtained at $5000 \mathrm{~Hz}$. The influence of air gap increases the sound absorption especially from $250 \mathrm{~Hz}$ to $4000 \mathrm{~Hz}$. These results indicate that fiber from Mesocarp is promising to be used sound absorbing material.
\end{abstract}

\section{Introduction}

Miscellaneous products of sound absorption panel have been created in market. Moreover, the common acoustical panels are made from glass wool, rock wool, slag wool and asbestos; which is harmful to human and sometime expensive. Some of synthetic material not only effect on human health but also contributes much higher Global Warming Potential (GWp) $\mathrm{kg} \mathrm{CO}_{2}$ [1]. Asbestos can cause asbestosis, lung cancer and mesothelioma [2]. Consequently, other natural fibers have been tested as alternative material such as coconut fiber [3], Kapok fiber [4], Arenga Pinnata [5], Paddy straw [6], Kenaf [7], Rice husk [8] and so on. Among these, oil palm Mesocarp is proving an interesting material because of low cost, low density, renewable, and saves for environment and human health.

At present, Malaysia is famous for the production of palm oil in the international market. Oil palm plantation showed a drastically increased in Malaysia. In 2011, about 5 million hectare of area oil palm has been planted [9]. Approximately $22 \%$ fiber produced from oil palm industry is a waste [10]. In addition, palm trees not only produce oil but provide a raw material such as oil palm (OPF), oil palm trunk (OPT), empty fruit bunch (EFB), palm kernel shell (PKS), palm kernel cake (PKC), palm kernel expeller (PKE), palm oil mill effluent (POME), dry decanter cake (DDC), ash and Mesocarp fiber [11]. Most of the oil palm fiber has been used widely in biomass media, mattress, 
fiber board, cushion, rugs, carpets, and rope manufacturing. Mesocarp fibers consist of cellulose and can very easily be made into chip particles rather that other wood-based.

This research is carried out to investigate the potential of oil palm Mesocarp fiber for sound absorbing material. The Mesocarp fibers were mixed with polyurethane (PU) as binder with ratio of 70:30. The percentage of the polyurethane had been used in literature [12-13]. The thickness was varied in $10 \mathrm{~mm}, 20 \mathrm{~mm}, 30 \mathrm{~mm}$, and $40 \mathrm{~mm}$. This study also investigated the air gap of $5 \mathrm{~mm}$ and $10 \mathrm{~mm}$ in the sound absorption performance [14]. The most important parameters to determine acoustic characteristics are the sound absorption coefficient. The measurement was done on accordance with ASTM E1050-98, which is the standard test method for impedance and absorption of acoustical materials using a tube.

\section{Metarial and Methods}

\section{A. Material Preparation}

The material that used in this study is Mesocarp fiber that obtained from oil palm mill and known as press fiber. These fibers are taken after the press station, as shown in Fig. 1. These fibers also include cellulose, hemicelluloses, lignin and other unwanted dirt's. Thus, the fiber were treated with $10 \%$ of alkaline treatment for 24 hours and dried at $70^{\circ} \mathrm{C}$ for 24 hours. The purpose of alkaline treatment is to remove unwanted dirt's, lignin and cellulose content and oil content. This treatment also will increase the surface roughness of the fibers, that will be increase the sound absorption capability and also increase the adhesion capability between the binder and fibers [15-16]. The dried fiber is mixed with polyurethane with ratio 70:30 and prepared the samples in cylindrical shape with diameter of $28 \mathrm{~mm}$ for high frequency measurements range from $125 \mathrm{~Hz}$ to $1600 \mathrm{~Hz}$ and $100 \mathrm{~mm}$ for low frequency measurements range from $1200 \mathrm{~Hz}$ to $6000 \mathrm{~Hz}$, as shown in Fig. 2.

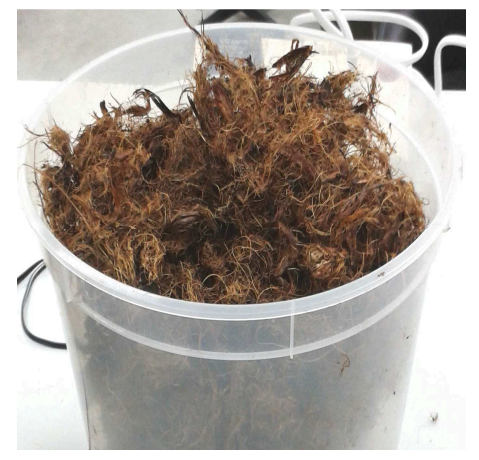

Fig. 1: Mesocarp fibers

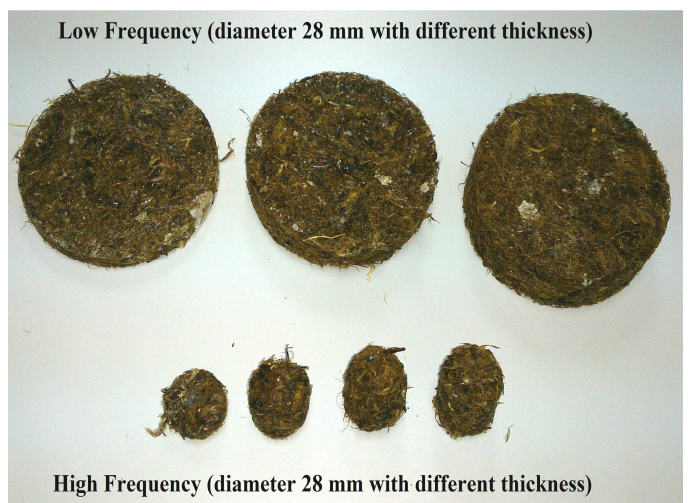

Fig. 2: Samples for Impedance Tube Method

\section{B. Sound Absorption Testing}

Impedance Tube Method (ITM) was used to obtain the sound absorption coefficient $(\alpha)$ which is based with ASTM E1050-09 standard. This method places a loudspeaker at one end of an impedance tube and a small sample of the material under test at the other end. The loudspeaker generates broadband, stationary random sound waves. The sound wave propagate within the tube strike the sample and is reflected resulting in a standing wave interference pattern. The sound absorption measurement was done by varied the thickness of Mesocarp fiber, $10 \mathrm{~mm}, 20 \mathrm{~mm}, 30$ $\mathrm{mm}$, and $40 \mathrm{~mm}$. The measurements are also performed with air gap of $5 \mathrm{~mm}$ and $10 \mathrm{~mm}$ at the back of the samples. 


\section{Result and Discussion}

\section{A. Sound Absorption Coefficient of Mesocarp Fiber}

In Fig. 4, it shows that the Mesocarp fiber is a good absorber especially for sample made of $40 \mathrm{~mm}$ thickness. The optimum sound absorption for Mesocarp fiber is 0.93 . The optimum values were obtained at frequency of $5000 \mathrm{~Hz}$. The result clearly shows that the sound absorption increases as the thickness is increased especially frequency ranged from 100 to $2000 \mathrm{~Hz}$. However, as the thickness increases, it will show insignificant effect on the results especially at higher frequencies. The result shows that the Mesocarp was a porous (fibrous) material: the demands for and significant thickness compared to sound wavelength make porous absorbers poor at low frequencies and they are good absorber at high frequencies [17]. Porous materials allow sound energy to easily enter and the low frequencies pass through material much easier than the high frequencies. Therefore, for the same material, thin material will not absorb as much low frequencies as will thicker material.

\section{B. Sound Absorption Coefficient of Mesocarp Fiber With Air Gap}

Testing were performed with and without air gap of $5 \mathrm{~mm}$ and $10 \mathrm{~mm}$ between the rear of the sample and the backing of movable plunger of the impedance tube. From figure 5 to 8 , introducing certain length of air gap increases the sound absorption performance especially frequencies at mid and high, despite decrease at certain range of frequencies. As the distance of air gap increases, the maximum peak value will also be different. It can be seen that as the distance of the air gap is increased, the maximum peak will move towards lower frequency. From the results, having an air gap will increase the sound absorption at certain frequency, where as the thickness increases, the peak point tend to move to lower frequencies for both samples. As seen in the figure, as the thickness is $10 \mathrm{~mm}$ and $20 \mathrm{~mm}$, the sound absorption increased within frequencies from 250 $\mathrm{Hz}$ to $3150 \mathrm{~Hz}$, while the thickness is $30 \mathrm{~mm}$ and $40 \mathrm{~mm}$, the sound absorption tends to increase at lower frequencies, from 100 to $1600 \mathrm{~Hz}$ and at higher frequencies from $4000 \mathrm{~Hz}$ to $5000 \mathrm{~Hz}$. Therefore, for the same amount of material, it is much better to have an air gap behind the layer, which has been confirm with the results and to improve sound absorption at mid and high frequencies.

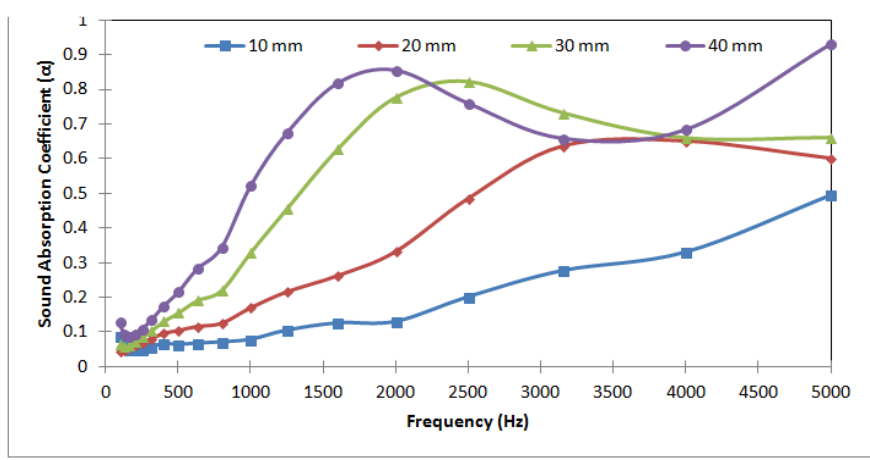

Fig. 4: Sound absorption of Mesocarp fiber with different thickness

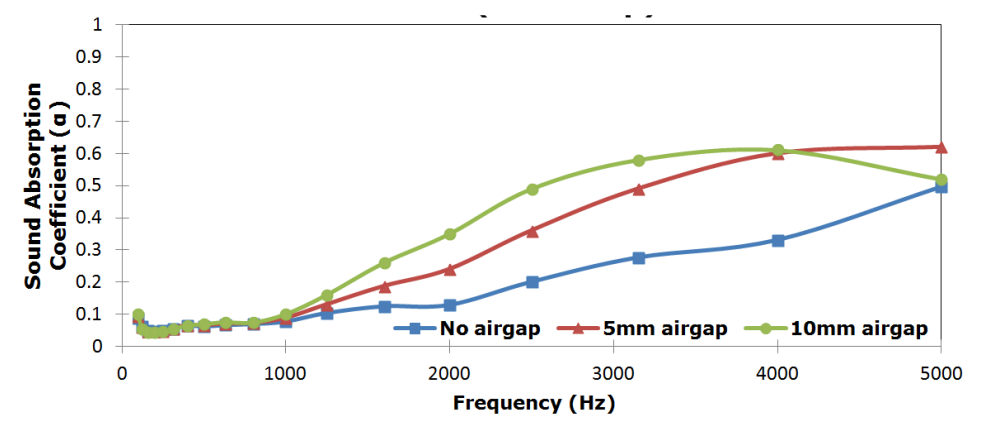

Fig. 5: Sound absorption of Mesocarp fiber with air gap of $5 \mathrm{~mm}$ and $10 \mathrm{~mm}$ at $10 \mathrm{~mm}$ thickness 


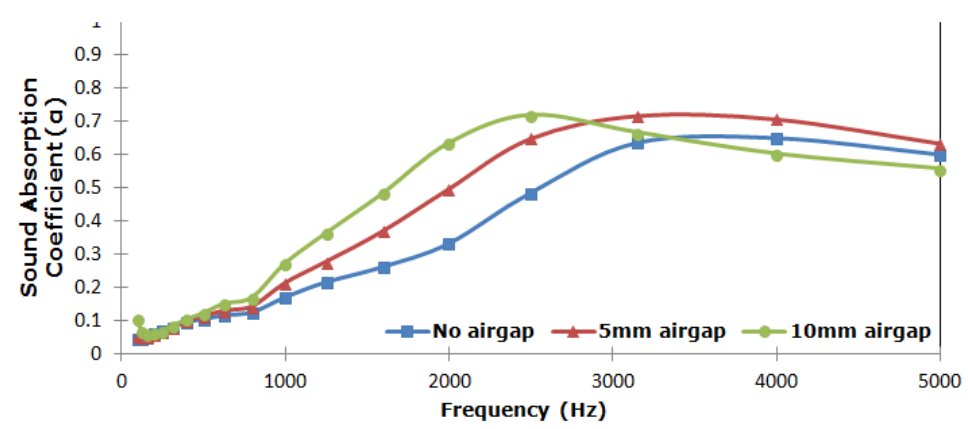

Fig. 6: Sound absorption of Mesocarp fiber with air gap of $5 \mathrm{~mm}$ and $10 \mathrm{~mm}$ at $20 \mathrm{~mm}$ thickness

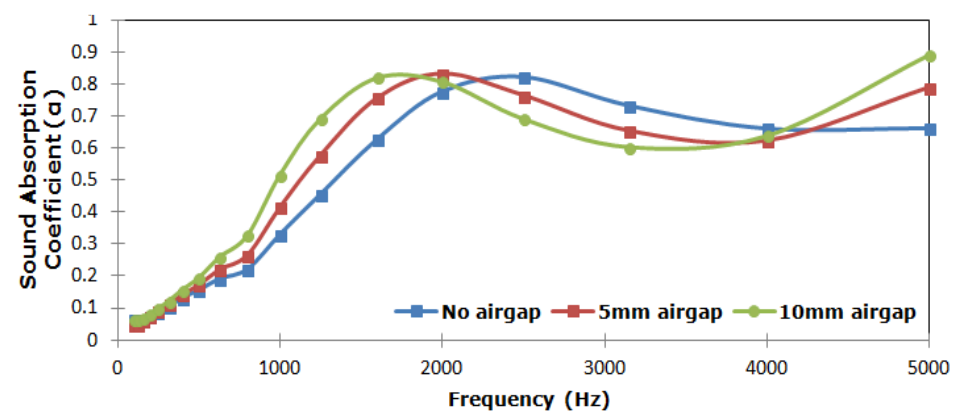

Fig. 7: Sound absorption of Mesocarp fiber with air gap of $5 \mathrm{~mm}$ and $10 \mathrm{~mm}$ at $30 \mathrm{~mm}$ thickness

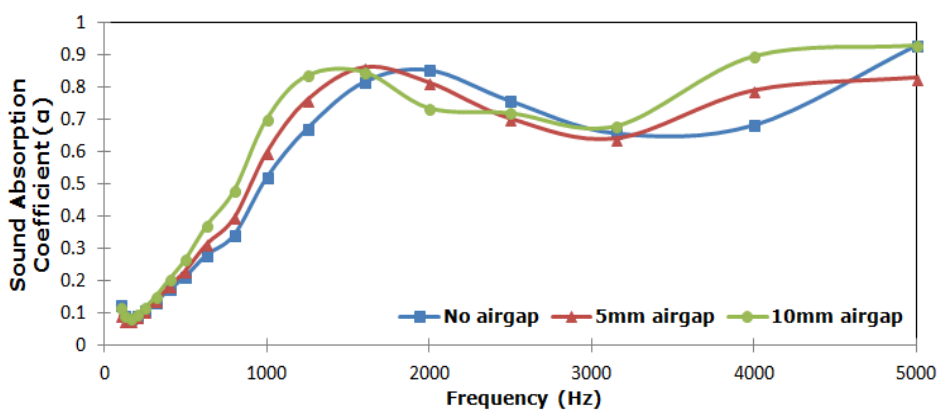

Fig. 8: Sound absorption of Mesocarp fiber with air gap of $5 \mathrm{~mm}$ and $10 \mathrm{~mm}$ at $40 \mathrm{~mm}$ thickness

\section{Conclusion}

The optimum sound absorption coefficient of Mesocarp fiber obtained at thickness of 40 $\mathrm{mm}$. The sound absorption coefficients were good from the medium to high frequency from 1600 $\mathrm{Hz}$ to $5000 \mathrm{~Hz}$ within the range of 0.7 to 0.90 . Air gap of $5 \mathrm{~mm}$ and $10 \mathrm{~mm}$ results in increasing of sound absorption especially at lower frequencies, from 250 to $3150 \mathrm{~Hz}$. Overall, panel made from Mesocarp fiber has good sound absorption properties and adding a certain thickness of an air gap were improve better absorption at low frequency. These results show that fiber from Mesocarp is capable to be used as raw material for sound absorbing material.

\section{Acknowledgement}

The author would like to thank to Office for Research, Innovation, Commercialization, and Consultancy Management (ORICC) and Centre for Graduate Studies Universiti Tun Hussein Onn Malaysia financial support in publishing this paper. (No. U044: The Study On Acoustical Performance Of Oil Palm Frond And Mesocarp Fiber) 


\section{References}

[1] S. N. Monteiro, F. P. D. Lopes, A. S. Ferreira and D. C. O. Nascimento, Natural-fiber polymermatrix composites : cheaper, tougher, and environmental friendly (2009), Jom 61(1), pp. 17-22

[2] E. Yano, Z. M. Wang, X. R. Wang, M. Z. Wang, Y. J. Lan, Cancer mortality among workers exposed to amphibole-free chrysotile asbestos, American journal of epidemiology 154.6 (2001), pp. 538-543.

[3] M. J. M. Nor, N. Jamaludin, F. M Tamiri, A preliminary study of sound absorption using multilayer coconut coir fibers. Electronic Journal Technical Acoustics (2004) 3, pp. 1-8.

[4] A. Veerakumar and N. Selvakumara, A preliminary investigation on kapok/polypropylene nonwoven composite for sound absorption. Indian Journal of Fibre \& Textile Research (2012) 37, pp. 385-388.

[5] L. Ismail, M. I. Ghazali, S. Mahzan, and A. M. A. Zaidi, Sound absorption of Arenga Pinnata natural fiber. World Academy of Science, Engineering and Technology (2010) 67, pp. 804-806.

[6] Y. Abdullah, A. Putra, H. Effendy, W. M. Farid, and M. R. Ayob, Dried Paddy Straw Fibers as an Acoustic Absorber: A Preliminary Study (2011), pp. 52-56.

[7] M. J. Saad, and I. Kamal, Kenaf Core Particleboard and Its Sound Absorbing Properties. Journal of Science and Technology (2013), 4(2), pp. 23-33.

[8] A. Zaidi, A. Mujahid, M. I. Ghazali, M. N. Yahya, and M. Ismail, Investigation on sound absorption of rice-husk reinforced composite. MUCEET (2009), pp. 19-22.

[9] Malaysia Palm Oil Board. Oil Palm Planted Area : 1975 - 2011 (Hectares). Economics \& Industry Development Division.

[10] K. H Badri, Z. B. Othman, I. M. Razali, Mechanical properties of poyurethane composites from oil palm resources. Iranian polymer journal (2005) 14(5), pp. 441-448.

[11] Cuah, C. K. (2009). Hoog Chan Trading. Retrieved May 6, 2014, from Product Provide: http://www.hoongchan.com/

[12] S. Mahzan, A. M. Ahmad Zaidi, N. Arsat, N. M. Hatta, M. I. Ghazali and S. Rasool Mohidden, Study on sound absorption properties of coconut coir fiber reinforced composite with added recycled rubber. International journal of integrated engineering 2, no 1 (2010), pp. 29-34. 
[13] L. Ismail, Acoustic and durability performances of Arenga Pinnata panel. Doctoral dissertation Universiti Tun Hussein Onn Malaysia (2012).

[14] H. S. Seddeq, Factors influencing acoustics performance of sound absorptive materials. Australian journal of basic and applied sciences, 3(4) (2009), pp. 4610-4617.

[15] X. Li, L. G. Tabil, S. Panigrahi, Chemical treatments of natural fiber for use in natural fiberreinforced composites: A review. Journal of polymers and the environment 15.1 (2007), pp. 25-33

[16] M. S. Islam, K. L. Pickering ad N. J. Foreman, Influence of alkali fiber treatment and fiber processing on the mechanical properties of hemp/epoxy composites. Journal of applied polymer science 119.6 (2011), pp. 3696-3707.

[17] D. A. Bies, C. H. Hansen, Engineering noise control : theory and practice. CRC Press (2009), pp. 302-308. 